\title{
LA NUEVA LEY ELECTORAL ITALIANA DE 2015, UN RETO PARA EL PARLAMENTARISMO DÉBIL
}

\author{
CARLO FUSARO \\ Catedrático de Derecho Público Comparado \\ Universidad de Florencia
}

\begin{abstract}
SUMARIO
I. Introducción.II. Constitución y fórmulas electorales en la Constitución italiana hasta la sentencia 1/2014. III. Las ocho leyes electorales para las elecciones al Parlamento italiano hasta la ley 52/2015. IV. Defectos y límites constitucionales verdaderos y presuntos de la ley $270 / 2005$. V. La sentencia $1 / 2014$ del Tribunal Constitucional italiano. VI. La ley n. ${ }^{\circ}$ 52, del 6 de mayo de 2015, denominadaltalicum. VII. La ley electoral, la reforma constitucional y la forma de gobierno italianas en la Europa del parlamentarismo difícil.
\end{abstract}

\section{INTRODUCCIÓN}

En mayo de 2015 el Parlamento italiano aprobó su tercera ley electoral desde 1993 , la quinta desde $1948^{1}$, y eso que nos estamos refiriendo únicamente a la elección de la Cámara de Diputados. Sin embargo, hasta hoy el bicameralismo perfecto indiferenciado italiano se ha caracterizado por tener dos cámaras, ambas elegidas de manera directa y ambas con los mismos poderes. Por tanto, en realidad las leyes electorales relevantes, desde 1948 hasta el presente, han sido nada menos que ocho (cinco para la Cámara de Diputados y tres para el Senado).

Con este artículo pretendemos presentar, enmarcándola en el contexto constitucional, político e histórico, la nueva ley; ilustrar cómo se inserta en la evolución de la forma de gobierno italiana de la época posterior a la II Guerra Mundial y cómo se vincula a la transición político-institucional que comenzó en los años

1 Se trata de la ley n. ${ }^{\circ}$ 52, del 6 de mayo de 2015,Disposizioni in materia di elezione della Camera dei deputati ( Disposiciones en materia de la elección de la Cámara de Diputados»). Como anteriormente, se trata de un conjunto de enmiendas al Texto Único del D.P.R. (Decreto del Presidente de la República) n. 361 , del 30 de marzo de 1957. Todas las leyes italianas pueden consultarse en: www.normattiva.it. 
90 del siglo xx; describirla en sus contenidos; analizar sus virtudes y defectos; indicar cómo se coloca más globalmente en el panorama de las formas de gobierno parlamentarias de Europa.

El caso es que el principal motivo por el que la nueva ley electoral ha suscitado un cierto interés fuera de Italia (más allá de los círculos restringidos de los expertos en cuestiones italianas) se encuentra en el hecho de que los últimos años marcan una creciente dificultad de funcionamiento del parlamentarismo: si en el pasado esta era una conocida especificidad italiana, hoy en día ya no es así. En diferentes países los cambios sociales y culturales de estas décadas han creado las condiciones para una fragmentación política sin precedentes que se refleja en la composición de muchas asambleas parlamentarias, en varios países. A menudo se hace mucho más difícil la formación de mayorías suficientemente estables y con un mínimo de homogeneidad, es decir, eficientes, lo que tiene efectos letales en la gobernabilidad precisamente en momentos de grandes retos tanto dentro como fuera de Europa. Naturalmente, esta difícil gobernabilidad de los países individuales se traduce también, a su vez, en una gobernabilidad más difícil a nivel de la Unión Europea.

La nueva ley electoral italiana nace con el objetivo preciso de posibilitar (por primera vez en Italia) el gobierno de partido en un contexto en el que las coaliciones no han funcionado nunca demasiado bien.

\section{CONSTITUCIÓN Y FÓRMULAS ELECTORALES EN LA CONSTITUCIÓN ITALIANA HASTA LA SENTENCIA 1/2014}

La Constitución italiana no dice nada respecto al sistema y a la fórmula electoral. A menos que uno quiera dedicarse a lo que el Tribunal Constitucional italiano llamó en su momento «constructivismo interpretativo» ${ }^{2}$ (es decir, la pretensión de deducir de principios muy generales las normas que le vengan bien a quien las interpreta, sin conexión alguna con el derecho positivo), es imposible extraer del texto de la Constitución de 1948 indicación alguna referida a esta cuestión.

El único artículo de la Constitución sobre el tema del voto es el artículo 48, que trata de cuestiones completamente diferentes (el electorado activo cuando se alcanza la mayoría de edad, establecida hoy en 18 años; la personalización del voto y la no admisión del voto por poderes; el igual derecho de voto para todos los ciudadanos; la libertad de votar sin interferencias o influencias indebidas; el secreto del voto; el voto como deber no estrictamente jurídico, sino «cívico», y la obligación moral no sancionable; las modalidades específicas de ejercicio del voto desde el extranjero para los ciudadanos allí residentes;los casos en los que se pue-

2 La fórmula se puede encontrar en la sentencia 6/1956. 
de limitar el derecho de voto). Como puede verse, no hay ninguna referencia directa o indirecta a la manera de transformar los votos en escaños (es decir, a la fórmula electoral o — más en general- al sistema electoral).

No es una casualidad, se trató de una decisión consciente. Los constituyentes, aun estando a favor muy mayoritariamente de fórmulas proporcionales, estaban también convencidos de que no era oportuno hacer cristalizar en la Constitución un método específico. Sabían que el contexto político podría cambiar y aconsejar soluciones diferentes a la proporcionalidad. Sobre esta cuestión, el 23 de septiembre de 1947 tuvo lugar en el hemiciclo una discusión que respondía a su vez a un orden del día sancionado anteriormente en la Comisióny que confirmaba el contenido de este: a propósito del sistema electoral, se estableció «concretar el sistema proporcional, aunque no se incluyera en la Constitución, para dejar al Parlamento, en la eventualidad de que fuera necesario para una situación particular determinada, libre para modificar el sistema electoral sin modificar la Constitución» ${ }^{3}$.

La Constitución italiana, por tanto, no impone ni prohíbe ningún sistema o fórmula electoral, a pesar de que en el pasado algunos expertos intentaran demostrar que contiene una prohibición implícita de los sistemas mayoritarios ${ }^{4}$; de igual manera, no se puede estar de acuerdo con la tesis según la cual la igualdad del voto (a la que se refiere el artículo 48 de la Constitución) debe entenderse en el sentido de que los votos de los electores individuales tienen el mismo peso no solo de entrada sino también de salida (es decir, en el resultado).

Hasta hace poco tiempo, también el Tribunal Constitucional se había manifestado siempre en este mismo sentido. Ya en la sentencia 43/1961 había afirmado lo siguiente:

«[...] la exigencia sancionada por el artículo 48 de la Constitución de que el voto $[\ldots]$ ha de ser también igual, refleja la votación en el sentido de que a esta los ciudadanos lleguen en condiciones de perfecta paridad [...] Cada voto [...] contribuye potencialmente y con igual eficacia a la formación de los órganos electivos [...] Sin embargo, $[\ldots]$ el principio de igualdad no se extiende $[\ldots]$ al resultado concreto de la manifestación de la voluntad del votante. El resultado depende, por el contrario, exclusivamente del sistema que el legislador ordinario, no habiendo establecido la Constitución ninguna disposición al respecto, ha adoptado [...]».

En 1995, además, el Tribunal afirmaba expresamente que el voto igual «no puede dar fundamento, por lo que respecta a los resultados de las votaciones, a la

3 Las actas de la Constituyente, incluidas las discusiones artículo por artículo, se pueden encontrar fácilmente en una página de Internet que las recopila: http://www.nascitacostituzione.it/index.htm (bajo la dirección de CalzaretTi F.).

4 LAVAGNA, C.: «Il sistema elettorale nella costituzione italiana» ( El sistema electoral en la constitución italiana», en Rivista trimestrale di diritto pubblico (Revista trimestral de derecho público), 1952, p. 849. 
obligación de una constitucionalizaciónde la opción de la proporcionalidad» (sentencia 429/1995; conforme también a la 107/1996 y a la 173/2005). En la sentencia 356/1998, el Tribunal legitimaba además los conocidos como «premios a la mayoría» (es decir, la atribución por ley a la lista o a las listas ganadoras (en caso de que se hubiesen presentado en coalición) de un número de escañosmajorityassuring igual a la mayoría absoluta del órgano representativo). En otra ocasión, al declarar la inadmisibilidad de una excepción de constitucionalidad presentada contra la cláusula de umbral mínimo de votos del $4 \%$ de la ley electoral 277/1993, el Tribunal afirmó que no existe «ante una hipotética inconstitucionalidad, una solución obligatoria, sino una pluralidad de soluciones», por lo que el Tribunal «no podría de ningún modo, según la misma jurisprudencia reiterada [...], sustituir al legislador en una decisión que le está reservada a este» (sentencia 438/1993). El Tribunal sostuvo, de nuevo, otra máxima: «[...] la determinación de las fórmulas y de los sistemas electorales constituye un ámbito en el que se expresa con el máximo de evidencia la cualidad política de las decisiones legislativas, censurables ante los tribunales de constitucionalidad solo cuando resultenmanifiestamente irracionales [...]» (sentencia 260/2002. La cursiva es mía, al igual que en las citas posteriores).

En la decisión con la que estableció la inadmisibilidad de los referéndums solicitados contra la ley electoral de 2005, el Tribunal rebatió implícitamente el concepto según el que la reforma electoral debe ser el fruto de decisiones discrecionales del legislador, negando que pueda, en ese caso, ser fruto de una intervención manipulativa mediante un referéndum abrogatorio (sentencia 13/2012, punto $5.4)^{5}$. En este mismo sentido va también la clara formulación de la sentencia 271/2010 (que se refería a las elección al Parlamento Europeo y que declaraba inadmisible incluso en sentido abstracto la excepción planteada, admitiendo que se pudiese sospechar de su potencial inconstitucionalidad), en cuyas palabras finales se puede leer: «solo puede corresponder al legislador señalar, con referencia específica al órgano representativo considerado, la solución más idónea para resolver la alegada incongruencia de la materia criticada. Ante una pluralidad de soluciones, ninguna de ellas constitucionalmente obligatoria, este Tribunal no podría sustituir al legislador en una decisión reservada a este (entre las más recientes, destaca la sentencia n. ${ }^{\circ} 58$ de 2010; disposiciones n. ${ }^{\circ} 59$ y n. ${ }^{\circ} 22$ de 2010)».

Es necesario añadir que tanto en la sentencia 13/2012 como anteriormenteen la sentencia 15/2008 (también esta sobre la admisibilidad de un referéndum, pero en este caso declarándose a favor), el Tribunal había permitido que se filtrase implícitamente una duda sobre la constitucionalidad de la ley 270/2005 (de la que hablaremos en elapartado III), señalando al Parlamento «la exigencia de considerar atentamente los aspectos problemáticos de una legislación que no subor-

5 Citado en Gratteri, A.: «In Europa votano così: Costituzioni e sistemi elettorali» («En Europa votan así: constituciones y sistemas electorales»), en Forumcostituzionale.it, 27 de septiembre de 2012. 
dina la atribución del premio de mayoría a que se alcance un umbral mínimode votos y/o de escaños», aun reconociendo que «cualquier sistema electoral implica un nivel más o menos consistente de distorsión en la fase conclusiva de la distribución de los escaños[...]». Sin embargo, bien mirado, también este obiter dictumconfirmaba toda la sabia jurisprudencia anterior.

\section{LAS OCHO LEYES ELECTORALES PARA LAS ELECCIONES AL PARLAMENTO ITALIANO HASTA LA LA LEY 52/2015}

Sin contar la ley 52/2015, durante las diecisiete legislaturas del Parlamento italiano (1948-2013) se han aplicado cuatro leyes electorales diferentes para la Cámara de Diputados y tres para el Senado de la República en un periodo de 65 años. A continuación las mencionamos brevemente, dado que esta larga historia constituye el marco en el que colocar la última reforma, de la que trata este artículo.

La Cámara de Diputados. La primera ley electoral de la era constitucional fue el Texto Único n. ${ }^{\circ} 26$, del 5 de febrero de 1948. Los diputados elegibles estaban subdivididos en 32 circunscripciones de un tamaño medio de entre 18 y 19 escaños; los partidos presentaban listas que contenían un número de candidatos no superior al número de escaños de la circunscripción; los electores votaban al símbolo del partido; además, podían formular hasta tres o cuatro votos de preferencia para uno, dos, tres o cuatro candidatos; el primer voto determinaba los escaños que se asignarían al partido, mientras que el voto o los votos de preferencia determinaban los candidatos a los que les serían atribuidos los escaños eventualmente conquistados por el partido ${ }^{6}$; los escaños se repartían de modo proporcionalcon elmétodo del cociente, corregido, eso sí, con un +2 (o, hasta 1956, con un +3) según el siguiente esquema: [votos expresados: (candidatos +2$)$ ]; los votos de cada lista se dividían por el cociente, con lo que se obtenían los escaños enteros atribuidos a la lista; sobraba así un cierto número de restos como escaños no asignados que confluían en Roma (en un distrito único nacional); aquí se atribuían, en función de los restos, a las listas que hubiesen obtenido al menos un cociente entero, además de un mínimo de 300000 votos (desde 1956). Se utilizaba de nuevo el método del cociente, pero sin correctivos: los posibles escaños no asignados pasaban a las listas con los restos mayores. Se trataba pues de un sistema proporcional con base en las circunscripciones; este sistema premiaba ligeramente a las listas mayores y establecía un modesto umbral mínimo de votos (de hecho, aparte de la media de 18-19 escaños por circunscripción, había, como en España con el caso de Madrid y Barcelona, dos circunscripciones muy grandes, Milán-Pavía y Roma-Viterbo-Latina-Frosi-

6 Este sistema - típico de la legislación electoral italiana desde antes del fascismo- pretendía combinar un sistema proporcional con la personalización del voto típica, por el contrario, de las circunscripciones uninominales. 
none, en las que se podía obtener un escaño entero con porcentajes de voto muy bajos, incluso de solo de alrededor del 1,5-2,0\%, que posteriormente disminuyeron cuando el número total de escaños pasó a ser de 630). En 1948 la Democracia Cristiana obtuvo con el 48,5\% de los votos el $53 \%$ de los escaños, y después ningún partido consiguió la mayoría absoluta ${ }^{7}$.

En 1953 se sancionó una importante modificación de esta ley que la transformó en la segunda ley electoral de la posguerra. La ley n. ${ }^{\circ}$ 148, del 31 de marzo de 1953, introdujo una regla en función de la cualla lista única o las listas coaligadas que hubiesen obtenidoal menos el $50 \%$ más uno de los votos válidos nacionales (es decir, la mayoría absoluta) obtendría u obtendrían 380 escaños (de un total de 590, es decir, el 64,4\% del total) más un «extra» (el conocido como «premio») de hasta casi el $15 \%$ respecto al porcentaje de los votos, y, por tanto, un premio de alrededor del 11-13\% de los escaños. Las demás listas se repartirían proporcionalmente los escaños restantes. Esta fórmula suscitó rechazos apasionados, fue tachada de «ley estafa» y llevó a algunos aliados a romper con la DC (que perdió más del $8 \%$ de los votos). Así, ninguna coalición obtuvo la mayoría absoluta de los votos, no se asignó el premio y se aplicó la fórmula proporcional ya vigente. La ley fue abrogada un año después, por la ley n. ${ }^{\circ} 615^{8}$, del 31 de julio de 1954. Se volvió entonces a la ley de 1948, que en 1956 sufrió algunas modificaciones: la reducción de +3 a +2 del correctivo para la determinación del cociente de circunscripción en función del cual se atribuían los escaños enteros; el añadido, como condición de participación en el reparto de los escaños con los restos, del requisito de los 300000 votos válidos en el plano nacional (un modestísimo umbral mínimo de votos de poco más del 1\%). Posteriormente, en 1963, se fijó el número de diputados en 630 (y de senadores en 315, electivos). Antes, el número de unos y otros era de, respectivamente, 1 por cada 80000 y 1 por cada 200 000 habitantes (véase la ley constitucional n. ${ }^{\circ}$ 2, del 9 de febrero de 1963). El sistema proporcional de 1948 modificado seguiría en vigor hasta 1993 . Se consolidó así, debido a que también eran de base proporcionaltodas las demás leyes electorales (municipales, provinciales, regionales, para las elecciones al Parlamento Europeo, además de para la elección del Senado, véase más adelante), la que sería llamada la república de los partidos (basada en la proporcionalidad), en función de la cual los electores en los diferentes niveles de gobierno atribuían con su voto a los partidos políticos las cartas (las fichas) con las que estos construían y des-

7 Para conocer la historia de las leyes electorales italianas de 1948, véase BETTINELLi, E.: Alle origini della democrazia dei partiti ( «En el origen de la democracia de los partidos»), Milán, Edizioni di Comunità («Ediciones de Comunidad»), 1982.

8 Esta ley, al igual que las posteriores ley 270/2005 y ley 52/2015, son comparadas por los críticos con la ley n. ${ }^{\circ} 2444$, del 18 de noviembre de 1923 (ley Acerbo). Esta atribuía el 66\% de los escaños a la lista ganadora, siempre que hubiera obtenido al menos el 25\% de los votos; la ley 148/1953 atribuía el 64\% de los escaños siempre que se hubiera obtenido almenos el 50\% más uno de los votos; la ley 270/2005 atribuía el $54 \%$ de los escaños sin un mínimo; la ley 52/2015 atribuye el $54 \%$ si se alcanza al menos el $40 \%$ de los votos o tras un segundo turno de votación (véase apartado VI). 
truían mayorías y gobiernos en un continuo hacer y deshacer (la duración media de los gobiernos italianos entre 1948 y 1994 fue de 11 meses, multiplicada por dos en los últimos 20 años; lo mismo sucedía hasta 1993 en los ayuntamientos de tamaño mediano-grande, en las provincias y en las regiones) ${ }^{9}$.

Con el impulso de eventos de importancia histórica (como el final de la división entre el este y el oeste en Europa) y de acontecimientos más propiamente italianos (como la inadecuación de los gobiernos, la no disponibilidad de los partidos ante una renovación del sistema y las pesquisas judiciales sobre la corrupción político-administrativa, es decir, las conocidas como investigaciones manos limpias), una minoría de la clase política y un poderoso movimientociudadano, apoyados por partes del establishment(cansadas de los costes insostenibles de un sistema político ineficiente y voraz), siguieron a finales de los años noventa la conocida como estrategia del referéndum para tratar, utilizando el instrumento legal del referéndum abrogativo previsto por el artículo 75 de la Constitución italiana, de obligar a cambiar a las fuerzas políticas renuentes.

Un primer referéndum se celebró en 1991: con casi el 96\% de síes de los votantes se alcanzó el limitado objetivo de reducir los votos de preferencia a uno solo (los votos triples o cuádruples se consideraban causantes de excesivo gasto, de corrupción y de creación de diferentes corrientes dentro de los partidos, es decir, de otro factor de inestabilidad). Sin embargo, el impacto político fue incluso mayor, puesto que se puso en evidencia la separación entre los ciudadanos y una buena parte del sistema de partidos. De hecho, dos años después un segundo referéndum (el 18 de abril de 1993) llevó, de nuevo por aclamación popular, con el $83 \%$ de votos afirmativos, a una transformación hacia el sistema mayoritario de la ley electoral para el Senado. Así, el Parlamento fue obligado a sancionar la tercera ley electoral para la Cámara de Diputados, la ley n. ${ }^{\circ} 277$, del 4 de agosto de 1993. Esta era radicalmente diferente a las anteriores. A los diputados se les dividía en dos grupos: 475 a elegir, con una primera papeleta, en igual número decircunscripciones uninominales (con un clásico sistema pluralityo firstpastthepost); 155 a elegir, con una segunda papeleta, en 27 circunscripciones plurinominales en función de pequeñas listas (formadaspor 5 o 6 candidatos de media), con método proporcional, pero repartiéndolos solo entre las listas que superasen el umbral mínimo de votos del $4 \%$, sustrayendo, eso sí, de los votos conseguidos por cada lista una parte de los votos obtenidos con la primera papeleta gracias a los cuales habían sido elegidos diputados en las circunscripciones uninominales (el denominado mecanismo «del desglose», es decir, de la sustracción). El sistema resultaba complicado y tenía como objetivo favorecer (en la parte proporcional) a las listas que hubiesen tenido menos éxito en la parte mayoritaria (con el fin de

9 Se puede encontrar una historia clásica de las instituciones y de la política en Scoppola, P.: La repubblica dei partiti: profilo storico della democrazia in Italia (1945-1990) ( LLa república de los partidos: perfil bistórico de la democracia en Italia (1945-1990)»), Bolonia, Mulino, 1991. 
reequilibrar). La parte proporcional, dejando de lado el reequilibrio representativo, perseguía dos objetivos: devolver a los partidos individuales la visibilidad autónoma que perdían en la parte uninominal mayoritaria y garantizar a los grandes partidos - en cualquier caso- una mínima presencia en todo el territorio nacional. Esta fórmula se aplicaría en las elecciones de 1994, 1996 y 2001, y contribuiría a producir una transformación integral del sistema político, una nítida bipolarización de la competición y el cambio periódico de los gobernantes (en 1994 ganaría el centro-derecha; en 1996, el centro-izquierda; y en 2011, de nuevo el centro-derecha). No sirvió para reducir la fragmentación del sistema de partidos ni, por ello, valió para garantizar la homogeneidad de las mayorías de gobierno, que siguieron estando encargadas a coaliciones, a menudo muy competitivas internamente, que no garantizaban ni la estabilidad de gobierno ni políticas de largo plazo. La legislatura 1994-1996 tuvo dos gobiernos; la legislatura 1996-2001 tuvo hasta cuatro (siempre del ámbito del centro-izquierda); la legislatura 2001-2006 de centro-derecha fue la única que en la práctica tuvo un solo gobierno (aunque formalmente fueran dos) ${ }^{10}$, liderado por Silvio Berlusconi.

Fue precisamente el tercer gobierno de Berlusconi el que sancionó una cuarta ley electoral. Era la ley n. ${ }^{\circ} 270$, del 21 de diciembre de 2005, aprobada con excepcional rapidez (en tres meses y con escasa oposición en el Parlamento, lo que ahora a menudo se olvida), a pocos meses de la renovación de las Cámaras, cuando la derrota del partido en el gobierno parecía segura (y se aspiraba a atenuar la victoria de la oposición, tal y como sucedió).La nueva ley no era una simple modificación, incisiva en mayor o menor grado, de las leyes electorales de 1993, sino una subversión de estas, funcional para los objetivos de los partidos de centro-derecha, que por aquel entonces eran Forza Italia («Fuerza Italia»), el Centro Cristiano Democratico ( «Centro Cristiano Democrático»), Alleanza Nazionale(«Alianza Nacional») y la Lega Nord per laPadania (Liga Norte de Padania) ${ }^{11}$.Desaparecían las circunscripciones uninominales y los escaños volvían a repartirse en base proporcional entre las listas de partido; la lista o las listas que - en coalición- obtuviesen más votos a nivel nacional (casi como si el país fuera una circunscripción única), obtenían al menos 340 escaños, con un posible (y muy probable)premiode cuantía variable (tanto mayor cuanto menor fuera el número de votos obtenido por la lista o las listas coaligadas vencedoras). De hecho, no existía un porcentaje mínimo de votos que alcanzar: era una especie de gigantesco siste-

10 Sobre el tema de la legislación electoral italiana de hasta aquel momento, véase FusAro, C.: Le regole della transizione ( «Las reglas de la transición), Bolonia, Mulino, 1995.

11 Los problemas del centro-derecha eran las dificultades para sumar los votos de las listas coaligadas y la debilidad de los candidatos de centro-derecha en las circunscripciones uninominales. Se las quería pues abolir y crear un sistema en el que el elector, votando a su propio partido, votase automáticamente a la coalición. Véase D’Alimonte, R., «Il nuovo sistema elettorale. Dal collegio uninominale al premio di maggioranza» («El nuevo sistema electoral.De la circunscripción uninominal al premio de mayoría»), en D'ALIMONte, R. y Chiaramonte, A.: Proporzionale ma non solo ( Proporcional pero no solo eso»), Bolonia, Mulino, 2007, pp. 51-88. 
ma first past the post nacional, de una sola vuelta, vuelta en la que también colaboraban en el éxito de la coalición las listas coaligadas que no superaban el umbral mínimo de votos. Solo había una papeleta, en la que el elector no encontraba ningún nombre, sino solo los símbolos de los partidos (unos al lado de los otros en caso de que estuvieran coaligados). Los elegidos se determinaban por el orden de lista preestablecido por quienes presentaban las listas. Sin embargo, cada candidato podía presentarse en cada una de las 26 circunscripciones regionales y subregionales, optando solo después por aquella en la que quería ser elegido, en caso de tener éxito en varias circunscripciones. Se incentivaba la formación de coaliciones mediante un mecanismo diversificado de umbral mínimo de votospor el cual las listas únicas tenían que superar el 4\%, las listas de coalición solo el 2\% (y, de hecho, estaba previsto que, en cualquier caso, la lista de coalición más votada de entre las que quedaran por debajo del $2 \%$ tambiénparticipase en el reparto de escaños). De esta manera se impulsaba a lo grande la relevancia del partido en cuestión (que era lo que pedían los aliados de Berlusconi), mientras que se exceptuaba la bipolarización de la competición y se garantizaba un ganador seguro. La ley 270/2005 se aplicaría tres veces: en 2006, en 2008 y en 2013, con resultados muy dispares. En 2006 se formaron dos coaliciones compuestas por muchas listas, pero las divergencias con la ley electoral del Senado (véase más adelante) provocó que el segundo gobierno de Prodi tuviese una existencia miserable, sostenido por demasiados aliados pendencieros y lejanos los unos de los otros a causa de sus programas; de hecho, las Cámaras se disolvieron menos de dos años después. En 2008 los dos partidos principales pusieron en práctica estrategias opuestas (con la misma ley), escarmentados de la lección anterior: el Popolo delle libertà («Pueblo de las libertades») de Berlusconi tuvo un solo aliado (la Lega); el PD de Veltroni, que había anunciado que se presentaría en solitario, contó también con un aliado(Italia dei valori, «la Italia de los valores»). Ganó Berlusconi, que no consiguió mantener unido su partido y que terminó arrollado por la crisis financiera mundial,que estaba ejerciendo presión sobre los títulos de la deuda italiana (los BOT, Bonos Ordinarios del Tesoro). Berlusconi fue sustituido por el gobierno de cuya formación se había encargada el tecnócrata Mario Monti, apoyado incluso por la oposición (además de por la antigua mayoría, sin la Lega). En 2013, por último, las elecciones al Parlamento de la XVII legislatura revelaron un inédito «cuatripolarismo», posteriormente transformado en una especie de «tripolarismo»: junto al centro-derecha liderado por Berlusconi y al Partido Democrático (por aquel entonces liderado por Pier Luigi Bersani), se había consolidado con un número similar de apoyos el recién nacido Movimento 5 Stelle («Movimiento 5 Estrellas»), singular movimiento ni de derechas ni de izquierdas fundado por el cómico Beppe Grillo ${ }^{12}$. Al igual que en 2006, la ley 270/2005

12 En cambio, tuvo poco éxito el pequeño grupo de centro liderado por Mario Monti: no obtuvo escaños suficientes como para resultar determinante y se disgregó, como grupo parlamentario, en los posteriores 
garantizó la formación de una mayoría en la Cámara de Diputados, pero no se logró lo mismo en el Senado. De ahí vino la ardua puesta en marcha de la legislatura, la dificultad durante varios meses de formar un gobierno, superada graciasexclusivamente a la reelección extraordinaria de Giorgio Napolitano como presidente. Este, en el discurso que pronunció ante las Cámaras reunidas el día de su juramento (el 22 de abril de 2013), espoleó a los grupos parlamentarios a llevar a cabo reformas constitucionales y electorales como condición - afirmópara que él se comprometiera a ocupar la esfera más alta del Estado (con casi noventa años de edad). Los partidos (con la excepción del M5S y de la Lega) lo aclamaron. Napolitano diría: «[...] ]me he encontrado de frente con las hipocresías de los partidos sobre las reformas, sus aseguraciones e incluso sus solemnes juramentos, cuando tocaba convencerme para superar mi resistencia y que aceptase el segundo mandato. $\mathrm{Y}$ en mi discurso $[\ldots]$ lo declaré sin medias tintas» ${ }^{13}$.

El Senado de la República. Italia es el único régimen parlamentario en el que también la ley electoral para la formación del Senado ha tenido hasta la actualidad una relevancia igual a la de la ley para la formación de la Cámara de Diputados, todo ello en razón de la absoluta paridad funcional de las dos cámaras del Parlamento, que hasta hoy ha conllevado también una doble relación de confianza entre el gobierno y cada una de las dos cámaras, elemento de extraordinaria complejidad en el funcionamiento del sistema parlamentario. En otras palabras: en Italia el problema de asegurar una mayoría en el gobierno se multiplica por dos.

El Senado siempre ha tenido una ley electoral al menos parcialmentediferente a la de la Cámara de Diputados. De hecho, durante los trabajos de la Asamblea constituyente las fuerzas políticas llegaron incluso a asumir el compromiso de adoptar, para la Cámara Alta, una ley electoral (ideada como mayoritaria) en función de las circunscripciones uninominales. Sin embargo, cuando en febrero de 1948 la propia Asamblea Constituyente examinó el proyecto del gobierno sobre este tema (que contemplaba precisamente las circunscripciones uninominales), hubo una especie de giro radical y fue aprobada la enmienda presentada por el democristiano Giuseppe Dossetti, apoyado por los demás grandes partidos, que subordinó la asignación del escaño en la circunscripción uninominal a la obtención del $65 \%$ de los votos; los escaños no asignados se distribuirían en función de una base regional (como dispone el artículo 57 de la Constitución) con método proporcional. Mientras esta ley permaneció en vigor, es decir, durante cuarenta y cinco años, solo se eligió a 50 senadores directamente en la circunscripción ${ }^{14}$. De este modo, el Senado tuvo como su primera ley electoral una ley basada en el reparto proporcional de los escaños, como la Cámara de Diputados; esta, sin embargo, premiaba más a los partidos mayores, puesto que se utilizaba, región por re-

meses y años.

13 Citado en Rosso, U.: «Riforme, non ci sarà una seconda chance» («Reformas, no habrá una segunda oportunidad»), en Repubblica, 8 de julio de 2016.

14 Fusaro, C.: obra citada, p. 41. 
gión, la fórmula d'Hondt. Hay que añadir que — presentando los partidos a sus candidatos coaligados entre sí en circunscripciones de un solo candidato, el votante no tenía capacidad de elección alguna sobre el candidato (ni podía saber quién lo sería, dado que tras el reparto proporcional regional de los escaños entre los partidos, los escaños se asignaban en las circunscripciones en las que los candidatos de cada partido hubiesen obtenido el porcentaje más alto de votos, un resultado imprevisible antes del escrutinio).

Hay que subrayar que cuando en 1953 la Cámara de Diputados sancionó la ley del premio de mayoría, no hubo ninguna modificación de la del Senado. La divergencia entre los dos sistemas no se consideró un problema, sino más bien una garantía (lo que no evitó una desatinada campaña contra la ley). No fue hasta 1993 cuando, tras un referéndum del que ya hemos hablado, se procedió a la aprobación de una segunda ley electoral totalmente diferente, también para el Senado; es más, sobre todo para el Senado: de hecho, el referéndum había tratado precisamente sobre su ley electoral, aprovechándose de cómo se había formulada esta con la aprobación de la enmienda Dossetti. El tema del referéndum de tipo abrogativo fue precisamente la abolición del quórum del $65 \%$ para la asignación de los escaños. De este modo, todos los escaños atribuidos en las 232 circunscripciones uninominales del Senado se transformaron en otros tantos del tipo plurality. Sin embargo, en 1963, cuando se estableció en 315 el número definitivo de los senadores electivos, no se instituyeron las nuevas circunscripciones uninominales que faltaban (315 menos, igual a 83). De hecho, el sistema se había transformado en proporcional, iy por ello nadie se preocupó del hecho de que hubiera más candidatos que circunscripciones! Ello permitió a los promotores delos referéndums sobre las leyes electorales de 1990-1993 proponer modificaciones que transformasen una ley falsamente mayoritaria, pero en realidad proporcional, en una efectivamente mayoritaria. Quedaban, eso sí, los 83 senadores que solo se podían elegir por el método proporcional. Este hecho se encuentra en el origen de la legislación mixta de mayoría portres cuartos y proporcional por un cuarto de 1993, que después - aunque fuera con reglas parcialmente diferentes — se amplió a la Cámara de Diputados (véase más arriba). La diferencia para el Senado estribó en que a todoslos candidatos se los presentaba uninominalmente y en que se los elegía según una base proporcional estrictamente regional solo por un cuarto, con una y no con dos papeletas, sin desglose pero también sin uso, obviamente, de los votos utilizados para elegir acandidatos uninominales.

Cuando en 2005 el centro-derecha volvió a intervenir en la ley electoral, el proceso fue el opuesto al de 1993 (véase la ley n. ${ }^{\circ}$ 270, del 21 de diciembre de 2005). En este caso el modelo adoptado por la Cámara de Diputados se adaptó y se amplió al Senado. Sin embargo, la adaptación, vinculada por la famosa «base regional», creó un monstruo: se dispuso (absurdamente) que el premio se asignase región por región y no en función de un resultado global nacional (como en la Cámara de Diputados), con el resultado de transformarlo en una lotería, condicionada además por el resultado de unas pocas regiones: bastaba con ganar en 
algunas de las más pobladas, aun perdiendo en la mayor parte de las demás o perdiendo como suma de votos nacionales (incluso perdiendo también en la Cámara de Diputados), para ganar en el total de los escaños región por región. En efecto, tanto en 2006 como en 2013 hubo mayorías diferentes en las dos cámaras del Parlamento. Por lo demás, también en el Senado las listas eran listas bloqueadas, no había preferencias, se votaba solo a los símbolos de las listas, había cláusulas de umbral mínimo de votos diferenciadas entre las listas coaligadas y las no coaligadas: del $8 \%$ para las no coaligadas (en el plano regional) y del $3 \%$ para las coaligadas.

Nadie (excepto los ex democristianos del CCD-CDU) puso objeción alguna al hecho de que tanto en la Cámara de Diputados como en el Senado los votantes no pudiesen dar indicaciones sobre los candidatos individuales a elegir: en el Senado siempre había sido así y en la Cámara de Diputados era así desde 1993; además, era lo normal en el panorama comparado de los modelos electorales proporcionales. Sin embargo, las dos leyes Calderoli (llamadas de esta manera por el apellido del ministro, aunque la ley era una sola, la 270/2005, que modificaba los dos textos únicos) tenían en común un defecto importante: no tanto justamente que quienes las presentabandeterminasen el orden de elección de los candidatos cuanto el hecho de que estos pudiesen presentarse, en la Cámara de Diputados o en el Senado, en todas las circunscripciones. Esto conllevó la elección de decenas de candidatos en muchas circunscripciones diferentes y la necesidad de una opción sucesiva sobre la circunscripción preelegida (en la Cámara de Diputados el día de la investidura, antes de que se utilizaran las opciones, solo 398 diputados pudieron participar ${ }^{15}$ ), opción que terminaba, eso sí, con el «castigo» de uno soloentre los primeros de los no elegidos, a discreción del candidato individual "plurielecto», del partido o de nuevo de quien lideraba el partido en función de los acuerdos que se hubiesen podido establecer. Incluso sobre estas bases se desarrollaría algún tiempo después la polémica que se demostró irresistible (a pesar de toda prueba contraria) sobre los candidatos conocidos como «nominados» (en la convicción de un presunto exceso de discrecionalidad de los partidos en la indicación de los candidatos) ${ }^{16}$.

También se celebraron referéndums abrogativos contra la ley 270/2005.Una primera serie prohibiría las coaliciones e impulsaría la asignación del premio solo a la lista ganadora tanto en la Cámara de Diputados como en el Senado; además,

15 Hasta 257 fueron las «plurielecciones» decididas por las opciones de solo 38 «plurielegidos» (elegidos en casi 7 elecciones de media). Los datos se pueden encontrar en Di Virgilio, A.: «Nuovo sistema elettorale e strategie di competizione: quanto è cambiata l'offerta politica» («Nuevo sistema electoral y estrategias de competición: cuánto ha cambiado la oferta política»), en D’Alimonte, R. y Chiaramonte, A.: Proporzionale ma non solo («Proporcional, pero no solo eso»), Bolonia, Mulino, 2007, pp. 219 y ss.

16 Muchos expertos han considerado esta cuestión relacionada con las modalidades de aplicación del art. 49 de la Constitución en lo referente al tema de la democracia interna de los partidos (en especial referencia a la selección de candidatos y a las repercusiones para esta cuestión de recurrir a las elecciones denominadas primarias). 
abrogaría la facultad de presentarse como candidato en más de una circunscripción (el conocido como referéndum Guzzetta, por el nombre de su primer promotor $\left.^{17}\right)$. Se celebraron los días 21 y 22 de junio de 2009: alrededor del $78 \%$ de los votantes optó por el «sí», pero la participación fue muy baja, inferior al $24 \%$, con lo que la consulta no fue válida. Una ulterior solicitud de referéndum se presentó en 2011 para abrogar la totalidad de la ley 270/2005, formulada de tal manera que, según los promotores (del llamado referéndum Parisi-Morrone, por los apellidos de sus dos promotore ${ }^{18}$ ) determinaría la reviviscencia (la vuelta a entrar en vigor) de las leyes electorales de 1993, pero en este caso fue el Tribunal Constitucional quien lo declaró inadmisible, negando la posibilidad jurídica de la reviviscencia (sentencia 13/2012). Así, las eventuales modificaciones volvían a estar disponibles exclusivamente para las Cámaras.

\section{LOS LÍMITES CONSTITUCIONALES VERDADEROS Y PRESUNTOS DE LA LEY 270/2005}

Una vez establecido que las resistencias en el Parlamento a la ley 270/2005 habían sido risibles, los límites de esa ley se demostraron evidentes desde el principio.Como era costumbre desde hacía varios años, contra esta ley se dirigió un alud de acusaciones de inconstitucionalidad, casi todas peregrinas y desacordes con la jurisprudencia del Tribunal hasta ese momento (véase apdo. II). En realidad, sin violar de forma expresa ninguna disposición constitucional, la reforma contenía dos motivos de inconstitucionalidad, uno difícilmente discutible, el otro en cualquier caso relevante: a) el primero era que excluía de la elección del gobierno los votos de los ciudadanos del Valle de Aosta; b) el segundo, que el criterio de asignación de los premios región por región en el Senado desafiaba el límite de lo razonable. Más en general, la previsión, con cualquier fórmula, de dos premios de mayoría distintos para cada una de las dos Cámaras en el marco de un bicameralismo como el italiano, en el que ambas son titulares de la relación de confianza, agrava, al acentuarlo, el riesgo estructural de dos mayorías contrapuestas (incluso más porque el electorado de las dos Cámaras en Italia es diferente: el Senado nunca ha sido elegido por sufragio universal, porque en su elección no participan los ciudadanos que aun siendo mayores de edad no hayan cumplido los 25 años. Véase el artículo 58.1 de la Constitución italiana).

Todas las demás objeciones de constitucionalidad le parecieron a quien esto escribe infundadas: cuestiones referentes al procedimiento legislativo de la ley 270/2005 (se especulaba con las presuntas violaciones de los reglamentos parla-

17 Giovanni Guzzetta es catedrático de derecho constitucional de la Universidad de Roma Tor Vergata y estuvo entre los promotores delos referéndums de 1990-1993.

18 Arturo Parisi, sociólogo, ha sido catedrático en Bolonia y ministro de Defensa en el segundo gobierno de Prodi; Andrea Morrone es catedrático de derecho constitucional en Bolonia. 
mentarios); la aprobación de la ley antes de que pasase un año desde las elecciones (lo prohíben los documentos del Consejo de Europa, pero se trata desoftlaw (derecho indicativo); el contraste con el resultado del lejano referéndum de 12 años antes (nunca considerado vinculante por el legislador); la previsión de un premio que alteraba la representación proporcional entre listas (pero hemos visto que la obligación constitucional de la proporcionalidad es inexistente); las modalidades de atribución del premio (particularmente en orden al número de votos mínimo exigido o no exigido); la cuantía del premio (para algunos demasiado alta, para otros demasiado baja); la presencia de umbrales mínimos de representación diferenciados; la contraposición con el art. 92 de la Constitución a causa de la previsión de que se depositen, junto a los símbolos, el programa y el nombre del líder (debido a la competencia del presidente de la República de nombrar al presidente del Consejo de Ministros); las listas denominadas bloqueadas (con el orden de los candidatos dictado por quien haya presentado cada lista) y la falta de preferencias (que, en cualquier caso, ya no existían desde 1993); y la falta de normas de protección de la representación de género ${ }^{19}$.

\section{LA SENTENCIA 1/2014 DEL TRIBUNAL CONSTITUCIONAL ITALIANO}

Con todo, sobre los principales contenidos de la ley 270/2005 se desarrollaría el más clamoroso y afortunado caso de strategiclitigationde la historia constitucional de la Italia republicana. Algunos ciudadanos, siendo el primer firmante el Abg. Aldo Bozzi (sobrino del miembro de la asamblea constituyente y parlamentario liberal que en 1983 había liderado la primera Comisión bicameral para las reformas institucionales), actuaron contra la presidencia del Consejo de Ministros y el Ministerio del Interior ante el tribunal civil de Milán, solicitando que este «constatara que su derecho de voto no había podido y no puede ser ejercido en coherencia con los principios constitucionales» (sic). El 18 de abril de 2011 el tribunal civil rechazó el recurso en cuanto al fondo y juzgó manifiestamente infundadas las excepciones de constitucionalidad presentadas. A la misma conclusión llegó el Tribunal de apelación de Milán, al que se recurrió con un, valga la redundancia, recurso del 24 de abril de 2012. Basándose en los precedentes, parecía que el resultado se podía dar por descontado, sobre todo considerando la indeterminación de la acción emprendida, cuya admisión equivalía a introducir un juicio de amparo o una Bundesverfassungsbeschwerde disfrazados, figuras jurídicas existentes en España y en Alemania, pero no en el ordenamiento italiano. Por este

19 Sobre este tema tratado en profundidad, véase FusAro, C.: La legge elettorale del 2005. Profili ordinamentali e costituzionali ( La ley electoral de 2005. Perfiles ordinamentales y constitucionales»), en D'AlimONTE, R. y Chiaramonte, A.: Proporzionale ma non solo ( Proporcional, pero no solo eso»), Bolonia, Mulino, 2007, pp. 89-119. 
motivo, la inadmisibilidad de la cuestión parecía pacífica (el juicio de constitucionalidad mediante proceso, en Italia, es concreto y posterior, no abstracto y preventivo; no se puede emprender en vía hipotética, sino solo en relación con un interés preciso del demandante por actuar).

Sin embargo, el demandante recurría ante la Corte de Casación: esta, por sorpresa, reconocía su interés por actuar; reconocía la relevancia de las excepciones de constitucionalidad presentadas en el proceso sobre la constatación «de la plenitud del derecho de voto», que, lo que es más, asimilaba como propias en una amplísima parte. A su vez, pocos meses después, el 4 de diciembre de 2013, el Tribunal Constitucional compartía la tesis de la admisibilidad «incluso de manera acorde con la exigencia de que no se libren de que su constitucionalidad sea debatida las leyes que [...] definen las reglas de la composición de los órganos constitucionales esenciales para el funcionamiento de un sistema democrático-representativo y que, por tanto, no pueden estar exentas de este debate sobre su constitucionalidad [...]» (sentencia 1/2014, punto 2). Decía, por el contrario, que se admitiría la existencia de una zona franca en el sistema de justicia constitucional.

En cuanto al fondo, el Tribunal juzgaba fundada la cuestión al declarar la inconstitucionalidad del premio de mayoría previsto por la ley tanto en la Cámara de Diputados como en el Senado. Aun reconociendo que la previsión del premio persigue un objetivo de relieve constitucional (estabilidad del gobierno y eficiencia de los procesos de decisión en el ámbito parlamentario), el Tribunal afirmó que la regulación de esa ley «no respeta el vínculo del menor sacrificio posible de los demás intereses y valores constitucionalmente protegidos [...] En definitiva, dicha regulación no es proporcionada respecto al objetivo perseguido, dadoque determina una compresión de la función representativa de la asamblea y del igual derecho de votoexcesiva y capaz de producir una alteración profunda de la composición de la representación democrática[...]», representación democrática a la que, por otra parte, el Tribunal, al hacer esta valoración evidentemente discrecional, reemplazaba. Para el Senado, en este caso con toda razón, si aceptamos los presupuestos apenas mencionados, el Tribunal añadía la valoración negativa de la multiplicidad de los premios regionales, que "produce el efecto de que la mayoría en el seno de la asamblea del Senado sea el resultado casual de una suma de premios regionales $[\ldots] »$.

Por último, el Tribunal censuraba también las modalidades de expresión del voto que «excluyen toda facultad del elector de influir en la elección de sus propios representantes [...] La elección del votante [...] se traduce en un voto de preferencia exclusivamente para la lista, la cual —en tanto que presentada en circunscripciones electorales muy amplias [...] - contiene un número muy elevado de candidatos [...] y los hace [...] difícilmente conocibles para el votante [...]» (la cursiva es mía, sentencia 1/2014, punto 5.1). «Una regulación como esta priva al votante de todo margen de elección de los propios representantes, elección que se entrega en su totalidad a los partidos» (léase: a quienes 
presentan las listas). La situación se veía agravada por la posibilidad de candidaturas múltiples. Lo que se considera inconstitucional es esta elección en grupo obligatoria: «condiciones de voto como estas [...], hacen a la regulación a examen no comparable ni con otros sistemas caracterizados por listas bloqueadas solo para una parte de los escaños, ni con otros caracterizados por circunscripciones electorales de dimensiones territorialmente reducidas, en las que el número de candidatos a elegir sea tan exiguo como para garantizar un cierto grado efectivo de conocimiento de los mismos [...](al igual de lo que ocurre en el caso de las circunscripciones uninominales)». De aquí la declaración de inconstitucionalidad de las dos leyes electorales, la de la Cámara de Diputados y la del Senado, «en la parte en la que no permiten al votante expresar una preferencia por los candidatos para determinar su elección $[\ldots .$. ».

Con la legislación electoral conocida como de restos, había pues dos leyes transformadas en completamente proporcionales (una a nivel nacional y la otra a nivel regional), con umbrales mínimos de voto restantes (a pesar de serincoherentes porque se mantenían diferenciados en función de coaliciones que perdían buena parte, si no toda, su razón de ser) y con la introducción de al menos un voto de preferencia, aun en ausencia de toda regulación. Insistimos en que había habido preferencias (múltiples hasta 1991, única en 1992) en la Cámara de Diputados, pero nunca antes las había habido en el Senado (ni siquiera cuando la distribución de los escaños era solo proporcional).Ello fortalecía políticamente la exigencia de llegar a una enésima nueva ley electoral.

Señalo, por último, algunas sentencias posteriores del Tribunal Constitucional que han sido interpretadas de diferentes maneras (incluso como una muy precavida toma de distancia parcial de la sentencia 1/2014). En la sentencia $275 / 2014$, referente a una ley electoral regional para los ayuntamientos de Trentino/Südtirol, esta ley electoral traía a la memoria su sentencia 107/1996 y numerosas otras sentencias relativas al hecho de que «el resultado concreto de la manifestación de voluntad del electorado (no) debe necesariamente ser proporcional al número de votos afirmativos otorgados, dependiendo en cambio de la posición concreta de cada una de las leyes electorales» (con referencia a las sentencias 39/1973; 6, 60 y 168/1963 y 43/1961).En la posterior sentencia110/2015, referente a una hipotética inconstitucionalidad del umbral mínimo de votos del $4 \%$ para las elecciones europeas, el Tribunal, al declararla inadmisible, parecía querer aclarar que la sentencia 1/2014 fue una excepción, en términos de admisibilidad, justificada solo por la imposibilidad, de presentar, de lo contrario, una cuestión de constitucionalidad por vía ordinaria incidental (en vista del art. 66 de la Constitución, que reserva exclusivamente a las Cámaras el control de los resultados electorales). Esta afirmación es relevante en relación con la reforma constitucional aprobada y sometida a referéndum, que introduce modificaciones en los artículos 73 y 134 de la Constitución, que preverían el recurso directo al Tribunal, antes de su promulgación, de leyes electorales por parte de un cuarto de los diputados o un tercio de los senadores (facultad expresamente ampliada por una norma 
transitoria a la ley $52 / 2015)^{20}$.Por último, en la sentencia193/2015, relativa a la ley electoral regional de Lombardía (en concreto en referencia al mecanismo de premiación y al umbral mínimo de votosprevistos por esta), el Tribunal juzgaba inadmisiblesalgunas de las cuestiones planteadas «en tanto que meramente hipotéticas». Aotras las juzgaba infundadas, reafirmando que «la previsión de umbrales mínimos de votos y la previsión de las modalidades para su aplicación [...] son típicas manifestaciones de la discrecionalidad del legislador [...]».

\section{LA LEY N. ${ }^{\circ}$ 52, DEL 6 DE MAYO DE 2015, DENOMINADA ITALICUM}

\section{El contexto y la tramitación legislativa}

El contexto en el que se relanza la discusión parlamentaria sobre la ley electoral es el de la ardua puesta en marcha de la XVII legislatura. Partida con impulso por la vía de las reformas tras la reelección extraordinaria del presidente Napolitano, promovida por el gobierno de Letta con una base del llamado amplio acuerdo (es decir, el PD, los centristas y el centro-derecha de Berlusconi: una especie de grosse Koalition a la italiana), ya en el otoño de 2013 se había producido una situación de bloqueo, a pesar del valioso trabajo de la Comisión de expertos nombrada por el presidente del Consejo de Ministros y presidida por el ministro de las Reformas Constitucionales, Gaetano Quagliariello, compuesta por 42 académicos (sobre todo constitucionalistas, pero también algunos politólogos, economistas de las instituciones y filósofos políticos). La Comisión había presentado sus conclusiones el 17 de septiembre de $2013^{21}$. En ellasse podía leerpor ejemplo lo siguiente: "particularmente coherente [...]resulta un sistema electoral de carácter proporcional con cláusula de umbral mínimo de votos rigurosamente selectiva ( $5 \%$ de los votos), con premio de mayoría que lleve hasta el 55\% de los escaños al partido o a la coalición ganadora que haya superado un determinado umbral [...] Por lo que respecta a los mecanismos de selección entre los diferentes candidatos, se puede pensar o en un sistema basado en un voto de preferencia y una segunda preferencia «de género», o bien, como alternativa, en un sistema que aúne circunscripciones uninominales para la mitad de los elegidos y una lista de tres o cuatro nombres para la otra mitad, con voto único [...] Según la opinión manifestada por varios componentes de la Comisión, el umbral para recibir el premio de mayoría debería ser de alrededor del $40 \%$ de los escaños. Según otros, el umbral debería ser más elevado, llegando al $50 \%$ de los escaños. Si en el primer

20 Sobre la reforma constitucional, véase Crainz, G. y Fusaro, C.: Aggiornare la Costituzione. Storia e ragioni di una riforma ( «Actualizar la Constitución. Historia y razones de una reforma»), Roma, Donzelli, 2016.

21 Las actas y las conclusiones enPer una democrazia migliore( «Por una democracia mejor»), Roma, presidencia del Consejo de Ministros, 2013, disponible en http://presidenza.governo.it/DIE/attività/pubblicazioni 
turno de votación ninguna lista o coalición de listas alcanza el umbral [...], se contempla un segundo turno de votación entre la primera fuerza y la segunda, atribuyendo a la ganadora global el $55 \%$ de los escaños ${ }^{22}$.

La iniciativa del gobierno de Letta encalló tras las reacciones a la declaraciónde expulsión del Senado de Silvio Berlusconi, por causa de una sentencia por fraude fiscal pasada en autoridad de cosa juzgada. Berlusconi y casi todo su partido abandonaron a la mayoría, que se vio en consecuenciareducida, aunque aún suficiente por pocos votos de margen (en el Senado). En cualquier caso, el gobierno se vio debilitado por ello. Poco después, en diciembre de 2013, el PD eligió, mediante asambleas internas y elecciones primarias abiertas a sus simpatizantes, a su nuevo secretario, en la persona del alcalde de Florencia, Matteo Renzi, de 38 años de edad, no parlamentario y que ya había sido derrotado por Bersani en las anteriores elecciones primarias asecretario. Renzi relanzó de inmediato la iniciativa sobre las reformas, buscando de nuevo el diálogo con el centro-derecha liderado por Berlusconi (Forza Italia). Por lo demás, desde la puesta en marcha de la legislatura, la tercera fuerza más votada, el M5S («Movimiento 5 Estrellas»), se había demostrado estratégicamente indisponible a cualquier forma de colaboración, tanto con el centro-izquierda como con el centro-derecha (incluso con el objetivo específico de plantearles problemas ante el electoradoal obligarlos a una colaboración impopular).

La ley electoral y la reforma constitucional fueron el objeto del acuerdo entre el nuevo secretario del PD, Renzi, y Silvio Berlusconi. En el plano de la ley electoral, Renzi propuso a Berlusconi discutir sobre tres hipótesis: a) un sistema de tipo español (proporcional y con circunscripciones muy pequeñas); b) un sistema del tipo de la ley electoral de 1993, pero modificada (circunscripciones uninominales, parte proporcional y sin desglose); yc) un sistema que fue llamado «del alcalde de Italia», es decir, una adaptación de las leyes electorales para la elección de los alcaldes (naturalmente, sin elección directa, pero con la asignación de una mayoría mínima que en el caso de los alcaldes es del $60 \%$ para la lista o listas ganadoras, con un posible segundo turno de votación en caso de que no se alcance un umbral mínimo de votos, lo que, en el caso de los ayuntamientos, supone la mitad más uno de los votantes).

El acuerdo se cerró sobre esta última hipótesis (además de sobre varios aspectos de la reforma constitucional), retomando casi punto por punto las conclusiones sobre este tema de la Comisión Quagliariello ${ }^{23}$. Este fue el contenido de la enmienda gubernamental presentada en la Cámara de Diputados (a la que el

22 En Per una democrazia migliore ( Por una democracia mejor»), Roma, presidencia del Consejo de Ministros, 2013, pp. 67-72.

23 Es necesario añadir que a los aliados menores del gobierno no les gustaba el sistema español, porque lo consideraban demasiado favorable para los grandes partidos, además de para aquellos fuertemente asentados a nivel regional, mientras que el sistema del tipo de 1993 no gustaba al centro-derecha berlusconiano por las mismas razones por las que se había cambiado esa ley en 2005. 
examen de la nueva ley electoral ya había sido remitido, aunque sin resultados) por el nuevo gobierno presidido por Matteo Renzi, que había sustituido al gobierno de Letta en febrero de 2014.

Continuaron siendo durante un tiempo objeto de discusión los siguientes temas: la cuantía del umbral para la asignación del premio (se comenzó con el 32\%, se elevó al $37 \%$ y después al $40 \%$ ); la cuantía del premio (que osciló entre los 325 y los 340 escaños); la cuantía del umbral mínimo de votos para el acceso al reparto proporcional de los escaños (que comenzó siendo de alrededor del 8\%, descendió al $4,5 \%$ y después al 3\%); y las modalidades de individuación de los elegidos (que al principio se refería a listas cortas pero bloqueadas y después se estableció sobre una solución mixta). La tramitación fue compartida entre la mayoría y Forza Italia (el partido de Berlusconi) durante todo el examen en primera lectura en la Cámara de Diputados y después también en el Senado. El 27 de enero de 2015, de nuevo, Forza Italia votó a favor de la reforma, del texto que se convertiría en definitivo, junto a la mayoría, solo para dar después un giro de 180 grados (incluso sobre la reforma constitucional paralela), tras las discrepancias provocadas por las modalidades de elección del nuevo presidente de la República, el juez constitucional y ya miembro del PD (y anteriormente de la DC), Sergio Mattarella, elegido el 3 de febrero de 2015. También tras este hecho la última y definitiva aprobación en la Cámara de Diputados fue difícil, y el gobierno tuvo que plantear una cuestión de confianza para conseguir la aprobación final, el 4 de mayo de 2015, sin ulteriores modificaciones que habrían devuelto el texto al Senado. Durante el primer examen en la Cámara de Diputados, la parte referente al Senado, inicialmente prevista, había sido tachada por petición de algunos diputados incluso de la mayoría, con la motivación de que no sería necesaria, dado el esfuerzo por hacer encallar más o menos de manera contextual la reforma constitucional que transformaría el Senado y, en todo caso, aboliría el sistema de la doble confianza.

Los votos favorables a la ley 52/2015 fueron el $58,4 \%$ del pleno del Senado (incluido todo el centro-derecha) y el 53\% del pleno de la Cámara de Diputados (muchos más, si no se tienen en cuenta las ausencias), más que en el caso de la ley Calderoli, en 2005 (51,2\%); poco menos que en el caso de la ley Mattarella en la Cámara de Diputados en 1993 (55,4\%); más que la ley Mattarella en el Senado, también en 1993 (39,3\%); ymás también que la ley de 1953 (52,6\%).

\section{Cómo funciona el sistema Italicum ${ }^{24}$}

La ley 52/2015 obedece a la técnica legislativa de la «novella» («cuento»): se trata de una ley que modifica el texto único 361/1957. La ley contiene más que

24 Los fenómenos de imitación son típicos del mundo político-periodístico, y no solo en Italia. Entre 1993 y 1994 el célebre politólogo Giovanni Sartori bautizó — para hacer un poco de sarcasmo gratuito— a 
la simple fórmula electoral, contiene un verdadero sistema electoral actualizado y, además: a) agudas disposiciones para promover la representación de género; b) el voto postal no solo para los residentes en el extranjero, sino también para quienes se encuentren temporalmente en el extranjero (durante al menos tres meses, como por ejemplo los estudiantes Erasmus); c) la aplicación efectiva del nuevo sistema solo desde el 1 de julio de 2016 (casi a modo de garantía sustancial de que no habría una disolución anticipada de las Cámaras) y d) un poder para que el Gobierno pueda individuar las circunscripciones electorales.

Volviendo al sistema electoral, se trata de un sistema con base proporcional del género majorityassuring, lo que constituye una radical modificación (pero no una subversión total) de la ley de $2005^{25}$. Funciona de la siguiente manera: a) las listas se presentan con candidatos subdivididos en 100 circunscripciones que, a su vez, forman parte de 20 circunscripciones regionales; estas circunscripciones tienen entre 3 y 9 candidatos (alrededor de seis de media); b) no se prevén coaliciones de listas diferentes (pero evidentemente son posibles las listas de coaliciones..., es decir, listas compuestas por candidatos de varias fuerzas políticas); c) cada fuerza política presenta — por cada circunscripción — una lista compuesta por un número de candidatos de como mínimola mitad y como máximo el total de los candidatos (por tanto, de entre un mínimo de dos a un máximo de nueve); se debe listar a los candidatos en orden alterno de género; también a nivel de circunscripciones (las regiones tendrán un mínimo de 1 circunscripción y un máximo de 17, como Lombardía, siendo la media de 5), la mitad de las candidaturas debe ser de un género, la otra mitad del otro; los requisitos de género deben satisfacerse so pena de no validez (por ello está contemplada la obligación de indicar cuatro suplentes, dos por cada género); d) cada lista de circunscripción prevé un o una cabeza de lista: el o la cabeza de lista es el hombre o la mujer a quien se le atribuye el primer o el único escaño conquistado por la lista en la circunscripción; e) el orden de elección de los candidatos siguientes al primero o primera es el determinado por los electores que disponen de una preferencia, o de dos, pero a condición de que la segunda preferencia sea para un candidato del género contrario al de la primera (si no es así, la segunda preferencia es nula);f) el cabeza de lista, y solo el cabeza de lista, cuyo nombre aparece impreso en la papeleta junto al símbolo de la lista, puede presentarse hasta en diez circunscripciones diferentes; los demás candidatos, por el contrario, solo pueden presentarse en una; sus nombres deben ser escritos a mano por el votante en una de las dos líneas situadas a la derecha del símbolo de la lista; g) está confirmado que las listas deben presentar en el Minis-

las leyes Mattarella trabucando en latín el nombre del ponente (Mattarellum). La idea tuvo éxito, y desde entonces todas las leyes e incluso las proposiciones de ley electoral de Italia han sido bautizadas, con mayor o menor fortuna y no solo en los periódicos, con nombres en latín.

25 Describimos aquí el sistema que atañe a 606 de los 630 diputados; de hecho, otras fórmulas regulan las elecciones de Trentino/Südtirol (once diputados), del Valle de Aosta (uno) y de la circunscripción del extranjero (doce). 
terio del Interior, junto al símbolo, el programa y el nombre del líder nacional de la lista; el o la líder no es por ello jurídicamente el candidato a la presidencia del Consejo de Ministros, porque esta decisión sigue correspondiendo al jefe del Estado. De hecho, es muy improbable que este nombre a alguien diferente al hombre o a la mujer que le haya sido indicado por la fuerza política ganadora de las elecciones; h) cada lista participa en el reparto de los escaños, que se realiza a nivel nacional, a condición de que haya superado el umbral mínimo del $3 \%$ de los votos totales válidos ${ }^{26}$; en Italia hoy en día esto equivale a alrededor de un millón de votos (pero, naturalmente, dependiendo también del porcentaje de participación en la votación, que suele estar en torno al $70 \%$ o un poco menos de las personas con derecho de voto); i) en la fase de escrutinio, sumando los votos llegados de las secciones y de las circunscripciones electorales, la Oficina Central Nacional determina el número de escaños que asignar a las listas que hayan obtenido al menos el $3 \%$ de los votos válidos; j) después, verifica si la lista con más votos ha conseguido al menos el $40 \%$ de estos; en caso afirmativo, verifica cuántos escaños ha obtenido y le asigna en cualquier caso 340 (el 53,9\% del total, el 55\% si no se toman en consideración los escaños extranjeros); asigna los otros 278 escaños a todas las demás listas que hayan superado el 3\%; el premio va, por tanto, de 0 a entre 70 y 75 escaños; la desventaja global para las demás listas de las que se sustraen (respecto al cálculo inicial estrictamente proporcional)estos escaños es de la misma cuantía; estas pierden entre el 0 y el $15 \%$ de los escaños que de lo contrario hubieran obtenido; k) si la lista ganadora obtiene menos del $40 \%$ de los votos válidos, se procede dos semanas después a un segundo turno de votación, en el que participa también la segunda lista que haya obtenido más votos en el primer turno; quien gana obtiene siempre 340 escaños; obviamente todos los electores tienen derecho a votar para decidir a quién asignar el premio; 1) llegados a este punto, se puede cerrar la asignación del total de los escaños a las listas; estos escaños se redistribuyen después entre las 20 circunscripciones y, a su vez, las Oficinas Centrales de las circunscripciones los redistribuyen en los distritos de la circunscripción entre las listas a las que correspondan; está garantizado el número total de escaños asignados a la circunscripción (según la población), no al distrito individual en la circunscripción (depende también del resultado comparativo de la lista en los distritos); $\mathrm{m}$ ) se proclama a los elegidos a partir de los cabezas de lista y siguiendo con los más votados con las preferencias. En el plazo de ocho días, los cabezas de listaplurielegidos deben comunicar al presidente de la Cámara de Diputados por qué distrito optan ${ }^{27}$.

26 En defensa de las minorías lingüísticas se admiten también las listas representativas de estas minorías quehayan obtenido al menos el $20 \%$ de los votosen una sola circunscripción regional.

27 Las pluricandidaturas de los cabezas de lista sirven para garantizar a los partidos (en especial a los partidos pequeños) óptimas probabilidades o incluso la certeza de que sus líderes sean elegidos. Por otra parte, es también verdad que cuantas más sean las pluricandidaturas, tantos más serán los escaños asignados en función de las preferencias. 


\section{Virtudes y defectos verdaderos y presuntos}

La ley 52/2015 persigue diferentes prioridades y propone decisiones dirigidas a acomodarlas, teniendo en cuenta, además, el dispositivo y los muchos principios afirmados (no siempre nítidamente, en especial si se diera la consideración adecuada a las aportaciones de la politología) por la sentencia 1/2014.

Veamos pues los objetivos del legislador: (primero) garantizar, en nombre de la estabilidad y continuidad de la acción de gobierno en un contexto político «difícil», decisionesdeterminantesque puedan devolver al cuerpo electoral y no a las negociaciones la elección del gobierno; (segundo) contener la fragmentación de los grupos parlamentarios; (tercero) garantizar a la vez una adecuada representatividad de la Cámara de Diputados, evitando que se reduzca excesivamente la representación de las fuerzas no ganadoras; (cuarto) evitar que para garantizar el primer objetivo se llegue a coaliciones «buenas para ganar, pero no para gobernar» por estar demasiado divididas internamente ${ }^{28}$; (quinto) fomentar el reequilibrio de género de la representación; $y($ sexto) respetar las indicaciones del Tribunal Constitucional.

Debido a que se optó por el sistema electoral descrito en B., la ley 52/2015 asigna un posible premio de cuantía variable que, sin embargo, tiene tanto un umbral para la asignación (el $40 \%$ de los votos o bien un segundo turno de votación) como un techo (no más de 340 diputados). Esto, considerando la cultura política italiana, confiere un margen muy reducido de solo 24 escaños respecto a la mitad más uno de 316: más que suficientes, pero solo si quien gana es capaz de mantenerse unido(lo que hasta hoy nunca ha ocurrido, al menos no sin haber recurrido continuamente a las cuestiones de confianza). El premio sacrifica la representatividad proporcional en una medida limitada y evita los efectos de los sistemas uninominales (a un turno, del tipo plurality, o a dos, como el tipo de Francia) que pueden llevar casi a borrar la presencia en el Parlamento de fuerzas políticas capaces de conseguir un número no marginal de apoyos (porcentajes del 10, 12,15 e incluso más). El umbral mínimo de votos es modesto (por lo que este sistema ha recibido algunas críticas), pero no irrelevante, y además va acompañado del voto decisivo y del premio. En el sistema de partidos italiano esto garantiza la entrada en la Cámara de Diputados de una pluralidad de fuerzas políticas mucho más allá de las tres o cuatro mayores del actual panorama de partidos. El premio se asigna a una sola lista, lo que debería favorecer la estabilidad de la mayoría. Es verdad que pueden establecerse listas de coalición, pero en cualquier caso el partido mayor tendrá la posibilidad de negociar acuerdos, necesariamente preventivos y sometidos al electorado, desde una posición ventajosa (lo que no sucede cuando hay un premio a coaliciones de listas distintas), unidas en igualdad por el

28 En el segundo gobierno de Prodi (2006) hubo representantes de quince partidos, mientras que otros aún estaban en mayoría. 
mismo programa y por el mismo líder. En cuanto a la selección de los elegidos por parte del votante, la ley contempla circunscripciones pequeñas, de entre 3 y 9 candidatos (de los que uno, el cabeza de lista, está resaltado en la papeleta); debería así garantizarse que estos seanen cierto grado conocidos, y además el votante podría contribuir a determinar quiénes serán los siguientes elegidos (naturalmente, esta posibilidad asumiría una mayor concreción para los partidos más votados, con mayores opciones de obtener más de un escaño en las circunscripciones individuales). La ley 52/2015, por último, en la larguísima historia electoral italiana, es la quegarantiza más rigurosamente, con mucho, la representación de género.

¿Cuáles fueron las críticas dirigidas contra esta ley? Hubo críticas de método (la ley fue votada, al final, únicamente por la mayoría, aunque la oposición de centro-derecha había votado, antes, el mismo texto; la ley se aprobógracias a la posición del gobierno sobre la cuestión de confianza). Hubo y hay críticas a su contenido: cuantía del premio, cuantía del umbral, premio a la lista individual y no a la coalición, presencia de cabezas de lista y posibilidad para los cabezas de lista de presentarse en varias circunscripciones. Estas críticas, como puede imaginarse, siempre son por una supuesta inconstitucionalidad. Las más insistentes se refieren a dos aspectos: a) el premio no prevería verdaderamente un umbral mínimo de votos para su asignación; para quien defiende esta postura, es como si el segundo turno de votación no existiese o no contase, y, por tanto, se lo confronta conel voto proporcional en el primer turno, el único considerado «genuino y verdaderamente legítimo»; obviamente, por definición, ninguna fuerza política alcanza el umbral impuesto en el primer turno ( isin el que no se celebraría el segundo!)..., ni tampoco puede haber un mínimo para acceder a la segunda vuelta, sin lo que no se entendería quién podría participar (en realidad, lo que no se quiere es el premio de mayoría ni el voto decisivo, como algunos expertos afirman públicamente); b) la presencia de los cabezas de lista llevaría a un excesivo poder de quienes presentan las listas para determinar quiénes serán los elegidos; como alternativa se proponen otros sistemas, como la abolición de los cabezas de lista y el uso de preferencias para elegir a todos los parlamentarios (con los efectos negativos que conllevaría. Sin embargo, no se debe olvidar que en 1991, por aclamación popular, las preferencias fueron reducidas, y no abolidas solo porque no era jurídicamente posible); sistemas uninominales de uno o dos turnos (pero, dejando de lado la distorsión de la representatividad, ciertamente mayor, ninguno de estos sistemas puede garantizar por sí solo elecciones decisivas en un sistema pasado a ser «tripolar» y destinado a permanecer así durante no se sabe cuánto tiempo ${ }^{29}$.

29 Para conocer una equilibrada crítica de la ley 52/2015, véase BARBERA, A.: «Italicum: più pregi che difetti» («Italicum: más virtudes que defectos»), enLa rivista il Mulino, 20 de abril de 2015, www.rivistailmulino.it/item/2780. Para conocer una opinión diferente, véase: PASQUINO, G.: «L'Italicum nelle condizioni date» («El Italicum en las condiciones dadas»), enIl Mulino, n. ${ }^{\circ}$ 4/2015, pp. 631-639. 


\section{4. ¿De nuevo una ley electoral inconstitucional?}

Como sucede siempre, también la tramitación de la nueva ley electoral impuesta por la sentencia $1 / 2014$ del Tribunal Constitucional fue fatigosa y condicionada no solo por los intereses percibidos por los partidos individuales, sino también por las relaciones entre estos, en continua evolución. Además, como suele suceder, algunas cuestiones de mera discrecionalidad política se transformaron en cuestiones de (presunta) inconstitucionalidad. En Italia, y no solo en Italia, invocar no la inoportunidad sino la inconstitucionalidad de las normas no gratas se ha convertido en una verdadera costumbre, sobre todo después de que el Tribunal, modificando su propia e inteligente postura anterior de prudencia, hubiese censurado, de manera discutible, la ley 270/2005, sustituyendo al legislador a la hora de confeccionar no una sino otras dos leyes diferentes (eligiendo efectivamente entre todas en las que se hubiese podido pensar).

La entrada en vigor de la ley 52/2015 y su aplicación desde el 1 de julio de 2016 no han apaciguado, sino más bien reavivado, polémicas y discusiones, aun más tras la aprobación de la ley de revisión constitucional de la parte segunda de la Constitución en abril de 2016 (sobre la que se ha pedido el referéndum ex art. 138.3 de la Constitución). De hecho, la ley de revisión transforma al Senado y suprime la doble relación de confianza, que permanece solo en la relación entre la Cámara de Diputados y el Gobierno.

Los mismos promotores de la strategiclitigation que había conducido a la sentencia1/2014 han vuelto así a proponer — generalizadamente, es decir, en decenas de tribunales, refiriéndose siempre a la sentencia $1 / 2014^{30}$, en particular a efectos de su admisibilidad - decenas de excepciones de constitucionalidad que algunos tribunales han decidido, al menos parcialmente, asimilar como propias, remitiendo las actas al Tribunal Constitucional ${ }^{31}$, que debería pronunciarse el 4 de octubre de 2016. Solo podemos esperar y ver, aunque no se debe olvidar que la extraordinaria sentencia1/2014 se decidió en el contexto de una prolongada parálisis de decisiones del sistema político y del Parlamento, a pesar de los diferentes compromisos asumidos por las fuerzas políticas desde la caída del tercer gobierno de Berlusconi (en noviembre de 2011) y corroborados con ocasión de la reelección de Giorgio Napolitano (en abril de 2013), una parálisis expresa y significativamente recordada en aquella sentencia. Hoy la situación es muy diferen-

30 Los recurrentes presentan un recurso «de acuerdo con el art. 702 bisdel código de proceso civil ante el Tribunal de Florencia solicitando la mera verificación de su derecho de votar en conformidad con la Constitución» (¡sic!), derecho supuestamente comprometido por una pluralidad de disposiciones de la ley 52/2015.

31 Tribunal de Mesina, disposición del 17 de febrero de 2016 (que ha establecido un récord de 16 posibles cuestiones, muchas de las cuales eran del todo inverosímiles); Tribunal de Turín, julio de 2016 (con solo 13 motivos, de los que un par fueron admitidos), mientras que otra está pendiente ante el Tribunal de Florencia. Sobre la disposición de Mesina, véase D’Amico, G.: «Adelante, Pedro,... si puedes». L'Italicum all'esame della Corte costituzionale ( El Italicum a examen del Tribunal Constitucional»), en Quaderni costituzionali, n. ${ }^{\circ}$ 2/2016, pp. 357-362. 
te debido a la firme puesta en marcha de un programa de reformas político-institucionales por parte de la XVII legislatura, lo que hace creer posible una recobrada prudencia por parte del Tribunal y un recuperado respeto por la discrecionalidad del legislador, la misma que en otros tiempos había sido repetidamente reconocida (y corroborada por las recientes decisiones citadas al final del punto V).

\section{LA LEY ELECTORAL, LA REFORMA CONSTITUCIONAL Y LA FORMA DE GOBIERNO ITALIANAS EN LA EUROPA DEL PARLAMENTARISMO DIFÍCIL}

En Europa, el tradicional gobierno de partido (el gobierno de un solo partido que gana las elecciones, como en la tradición británica y también en la tradición, más joven, de la España postfranquista) se ha convertido en una excepción ${ }^{32}$.

No solo la formación de mayorías depende de coaliciones, sino que estas tienden a ser coaliciones por necesidades cada vez más numerosas. En muchos casos se debe recurrir a las denominadas «grandes coaliciones», es decir, a coaliciones de partidos que se presentaron como alternativos y que anteriormente se habían efectivamente alternado en el poder (así ocurrió en Alemania por primera vez en 1972, y después de nuevo en 2009 y 2013; y así fue también en Austria). Las consecuencias son de diferente naturaleza: debilitamiento del papel de la oposición dentro de las aulas parlamentarias (por ejemplo, actualmente en Alemania la mayoría cuenta con casi el $80 \%$ de los escaños delBundestag); debilitamiento ante la opinión pública de los partidos tradicionales, «obligados» a compromisos, y en particular del partido más pequeño,forzado a apoyar a gobiernos liderados por el partido competidor (como es el caso del partido Liberal Demócrata en el Reino Unido y también del SVP en Alemania). Ocurre así que las grandes coaliciones tienden a perpetuarse, dado que, reduciéndose el consenso sobre los partidos tradicionales a favor de los alternativos, las motivaciones que imponen las grandes coaliciones se refuerzan (pero con un sumatorio de consensos cada vez más reducido).

En otros casos, por último, se recurre (y, para ser sinceros, no desde hace poco tiempo) a gobiernos de minoría, lo que vale sobre todo para los países escandinavos, habituados desde hace décadas a esto y algunos de ellos dotados de disposiciones constitucionales específicamente ideadas para facilitar el gobierno de partido minoritario (resulta emblemático el caso de la Constitución de Suecia de 1974). Sin embargo, tampoco esta es una solución fácil de exportar: ha funcionado mal en Italia, no parece que se la acepte en España, ni, por lo que se puede suponer, en

32 Sobre estos temas me remito a FuSARO, C.: Le trasformazioni del modello Westminster e le difficoltà crescenti del governo parlamentare in Europa («Las transformaciones del modelo Westminster y las crecientes dificultades del gobierno parlamentario en Europa»), en BAGNi, S.-FigueroA, G.A.-PAVANi, G.: La ciencia del derecho constitucional comparado. Homenaje al Profesor Lucio Pegoraro, Ciudad de México, en vías de publicación. 
Alemania, pero incluso en Escandinavia se necesita un gran esfuerzo colaborativo para aceptar que gobierne, incluso en solitario, un partido que haya obtenido 34 escaños de un total de 179. Este es el caso de Dinamarca tras las elecciones de $2015^{33}$.

La solución italiana de la ley electoral denominadaltalicumpara señalar su especificidad, basándose en una experiencia consolidada y en pruebas anteriores, puede efectivamente constituir un modelo. En efecto, estuvo en la base de las reformas del sistema político institucional de Armenia (2015-2016) ${ }^{34}$, fue tomada en consideración por algunos comentaristas en Israel ${ }^{35} \mathrm{y}$ parece haber suscitado algo de interés también en la España de las dos elecciones celebradas en un periodo de 6 meses.

En efecto, el Italicum combina elementos proporcionales y elementos mayoritarios en formas originales que merecerían ser evaluadas con pragmatismo y no criticadas a priori por ser supuestamente innaturales. Lo cierto es que no hay nada natural en las fórmulas electorales, sean las que sean, y que incluso desde un punto de vista teórico no existe razón por la que el reparto proporcional de los escaños sea «la» fórmula base por excelencia en función de la que valorar cualquier otra para medir la importancia de un posible «alejamiento». Esta postura es hija de un equívoco. Es necesario partir de un análisis correcto de las características de los regímenes parlamentarios, de todos los regímenes parlamentarios. Estos, a diferencia de los presidencialistas, precisamente en virtud de su naturaleza (que se fundan en la relación de confianza necesaria entre el gobierno y la asamblea política), exigen que la formación de esa asamblea garantice no solo la clásica función representativa sino también, segúnel contexto, las premisas de la gobernabilidad. Es un problema que, con toda evidencia, los sistemas presidencialistas no tienen: el cuerpo electoral elige en paralelo al más alto cargo del ejecutivo y a la asamblea; la investidura del primero no depende de la composición de la segunda. Ello garantiza la libertad de elegir más libremente a qué fórmula confiar la composición del Parlamento.

En el régimen parlamentarista, en cambio, la elección de la asamblea tiene una doble función y, por tanto, deben aplicarse (a riesgo de que se produzca la parálisis o el mal funcionamiento del sistema) fórmulas electorales que, en el contexto de partidos dado, permitan - con un elevado grado de probabilidad, salvo, naturalmente, algunas excepciones- desempeñar tanto la función de dar

33 Tantos son los escaños del partido del primer ministro Lars L. Rasmussen, alrededor del 19\% del total. El gobierno cuenta con el apoyo externo de otros tres partidos que suman otros 55 escaños. El total es de 89.

34 Véanse el art. 89 de la Constitución de la República de Armenia una vez enmendada tras el referéndum del 6 de diciembre de 2015 y el borrador del Código electoral en vías de adopción (véase Council of Europe, CDL-REF(2016)018).

35 ARENS, M.: Israel's formula for a stable government lies in Italy, en Haaretz, 18 de mayo de 2015, véase http://www.haaretz.com/opinion/.premium-1.656831. 
representación como la de establecer las bases de la formación (y el mantenimiento) de una mayoría eficiente.

La ley electoral italiana en su actual formulación da suficientes garantías a este respecto (aun sin la posibilidad, obviamente, de certezas absolutas), y, confrontada con sistemas de base íntegramente mayoritaria (tanto a uno como a dos turnos o con un segundo escrutinio de distrito), impone —en nombre de la gobernabilidad - sacrificios inferiores a estos últimos. También estasacrifica ciertamentela representatividad, pero en una medida relativamente marginal. En palabras llanas: (en Italia) no pueden darse casos como el del UKIP en el Reino Unido o el del Frente Nacional de Marine Le Pen en Francia (partidos que obtienen elevados porcentajes de voto sin ninguna o con escasísima representación parlamentaria, literalmente uno o dos escaños). Con el Italicum,por ejemplo, un partido que alcance el umbral mínimo de votos del $3 \%$ obtiene 15 o 16 escaños en vez de alrededor de 18 o 19, menos que la proporcionalidad estricta en función de los votos, pero una representaciónrebajada en no más del $20 \%$ con respecto a la proporcionalidad. Ello no basta: en contextos en los que resulta difícil atribuir la competición electoral a esquemas bipolares, las fórmulas mayoritarias de uno o dos turnos no ofrecen ninguna garantía de conducir a la investidura electoral de una mayoría (ni de un líder), menos aún en presencia de diferencias significativas en el sistema de partidos en las diferentes circunscripciones del país.

Por estos motivos, y en espera de que se idee alguna otra fórmula, el Italicum, incluso desde el punto de vista estrictamente constitucional, representa un buen acuerdo. Merecería que se aplicara durante alguna legislatura antes de ponerlo en tela de juicio antes incluso de que se utilice ${ }^{36}$.

$$
* * *
$$

TITLE: The new electoral law of 2015 in Italy, one challenge for the weak parliamentarism

ABSTRACT: Parliamentary regimes, the most adopted in Europe, are showing serious dysfunctions in many countries. Italy, whose 1948 Constitution does not provide any solution meant to stabilize the political and institutional system (the country has counted 63 cabinets in less than 70 years), has tried to solve these issues recurring to specifically crafted electoral laws. This article provides contextual bistorical and political analysis and describes features, merits and flaws of Law 52/2015, which introduces as.c. majority assuring electoral formula.

36 Esto es lo que está ocurriendo, por razones contingentes exclusivamente políticas, en Italia en vista del referéndum constitucional del otoño de 2016, que está relacionado con la reforma solo de manera indirecta. La cuestión central es que la ley electoralmajorityassuring se une a la abolición del mecanismo de la doble confianza (innovación ya de por sí más que descontada, necesaria y urgente), pero haciendo hablar del riesgo de excesiva concentración de poder a quienes confunden con autoritarismo cualquier intento de fortalecer el ejecutivo.De ahí el relanzamiento de las propuestas para cambiar una reforma tan fatigosamente encallada. Véase por ejemplo Falci, G. A.: Modificare l'Italicum? ( ¿Modificar el Italicum?"), en elCorriere della Sera del 11 de julio de 2016, p. 13. 
RESUMEN: El parlamentarismo — la forma de gobierno europea por excelencia - está manifestando en muchos países europeos graves dificultades de funcionamiento. Italia, cuya Constitución de 1948 carece de instrumentos de racionalización del sistema (tanto como para haber tenido 63 gobiernos en menos de 70 años), se ha decantado por leyes electorales específicamente estudiadas para hacer frente a este problema. Este articulo ofrece una contextualización bistórica y constitucional, y describe características, virtudes y defectos de la ley 52/2015, que es del tipo denominado majorityassuring.

KEY WORDS: Elections, form of government, parliamentary regime, electoral laws and electoral formulas, Italy.

Palabras Clave: Elecciones, régimen político, forma de gobierno parlamentaria, leyes electorales, Italia.

FECHA DE RECEPCIÓN: 10.06.2016

FECHA DE ACEPTACIÓN: 27.07.2016 